\title{
Pesquisa de anticorpos anti-Neospora spp. e anti-herpersvírus equino em cavalos de tração no município de Santa Maria, RS, Brasil
}

\author{
Looking for antibodies anti-Neospora spp. and anti-equine herpersvirus in carter horses in Santa \\ Maria, Brazil
}

\author{
Luís Antonio Sangioni* Sônia de Avila Botton ${ }^{\mathrm{I}}$ Juliana Felipetto CargneluttiI \\ Gustavo Cauduro Cadore ${ }^{\mathrm{II}}$ Alfredo Skrebsky Cezar ${ }^{\mathrm{I}}$ Rudi Weiblen ${ }^{\mathrm{II}}$ \\ Sonia Terezinha Anjos Lopes ${ }^{\mathrm{III}}$ Fernanda Silveira Flores Vogel ${ }^{\mathrm{I}}$
}

\section{- NOTA -}

RESUMO

O presente estudo teve como objetivo investigar a ocorrência de anticorpos contra Neospora spp. e o herpesvírus equino (EHV) em soros de cavalos de tração de Santa Maria, $R S$, Brasil. Os soros sanguineos provenientes de 91 animais do projeto de extensão da Universidade Federal de Santa Maria "Programa de Ação Social Amigos do Carroceiro" (PASAC) foram colhidos no período de março de 2006 a maio de 2008 e submetidos ao teste de imunofluorescência indireta para detecção de anticorpos anti-Neospora spp. e à técnica de soro neutralização para anticorpos anti-EHV. Constatou-se que $15,4 \%$ (14/91) das amostras foram reagentes para o Neospora spp. e não se verificou a presença da infecção pelo herpesvírus equino. Sugere-se a circulação do coccídeo na população equina estudada. Salienta-se a necessidade de estudos adicionais sobre o potencial risco zoonótico e a importância sanitária desse protozoário nos cavalos de tração.

Palavras-chave: EHV, neosporose equina, soroneutralização, imunofluorescência.

\section{ABSTRACT}

This study aimed to investigate the prevalence of antibodies against Neospora spp and equine herpesvirus (EHV) among carter horses in Santa Maria, RS, Brazil. Serum samples from 91 horses, involved in the extension project "Programa de Ação Social Amigo do Carroceiro" at Universidade Federal de Santa Maria, were collected from March of 2006 to May of 2008. Immunofluorescence assay was used to detect Neospora spp. and virus neutralization assay to EHV. This research showed $15.4 \%$ (14/91) samples were positive to Neospora spp. and no antibodies against EHV were detected. These results suggest the presence of Neospora spp. in carter horses of Santa Maria. Additional studies are needed to determine the zoonotic potential risk and the sanitary importance this protozoan in the population analyzed.

Key words: $E H V$, equine neosporosis, virus neutralization, immunofluorescence.

O Brasil comporta o terceiro maior rebanho mundial de equinos, sendo que o Rio Grande do Sul possui significativo destaque nesse contexto (FAO, 2007). Nos países de economia ascendente, assim como o Brasil, os cavalos utilizados para tração têm desempenhado importante papel na subsistência de várias famílias de baixa renda (reciclagem de lixo urbano). Alguns protozoários e vírus são importantes agentes de enfermidades neurológicas, respiratórias e reprodutivas em equinos, destacando-se o Neospora spp. (VILLALOBOS et al., 2006; DUBEY et al., 2003) eo EHV-1 eEHV-4 (CARVALHO et al., 2000; FLORES et al., 2007). O Neospora spp. é um parasita intracelular obrigatório que apresenta duas espécies: o $N$. caninum, relatado em cães (hospedeiro definitivo) e em várias espécies de animais (hospedeiros intermediários) e o N. hughesi, que infecta equídeos. O Neospora spp. pode se disseminar em populações susceptíveis tanto

'Universidade Federal de Santa Maria (UFSM), Centro de Ciências Rurais (CCR), Departamento de Medicina Veterinária Preventiva (DMVP), Laboratório de Doenças Parasitárias (LADOPAR). Av. Roraima, 1000, sala 5149, prédio 44, Camobi, 97105-900, Santa Maria, RS, Brasil. E-mail: lasangioni@gmail.com. *Autor para correspondência.

"UFSM, CCR, DMVP, Setor de Virologia, Santa Maria, RS, Brasil.

"IIUFS, CCR, Hospital Veterinário, Laboratório de Análises Clínicas Veterinárias (LACVET), Santa Maria, RS, Brasil 
pela transmissão horizontal quanto pela vertical (DUBEY et al., 2003). Em equinos, a neosporose pode causar doença reprodutiva e/ou neurológica (LOCATELLI-DITTRICH et al., 2006). A pesquisa de anticorpos anti-Neospora ssp. em equinos no Brasil ainda é escassa e os estudos disponíveis têm revelado índices bastantes variados (2,5 a 47\%) (DUBEY et al., 1999a; HOANE et al., 2006; LOCATELLI-DITTRICHet al., 2006; VILLALOBOS et al., 2006).

O EHV-1 e EHV-4 são vírus DNA, pertencentes à família Herpesviridae e determinam infecções latentes (FLORES et al., 2007). A infecção pelo EHV-1 pode causar diferentes sinais clínicos (doença respiratória, reprodutiva, nervosa e neonatal fatal) (CARVALHO et al., 2000). O EHV-4 causa doença respiratória e raramente ocasiona abortos em equinos (CARVALHO et al., 2000). Normalmente, os animais mais velhos constituem a fonte de infecção após episódios de reativação do vírus latente (FLORES et al., 2007). A infecção pelo EHV-1 foi relatada em abortos equinos em São Paulo, Minas Gerais e Rio Grande do Sul (NILSON \& CORRÊA 1966; VARGAS \& WEIBLEN, 1991; MOREIRA et al., 1998) e disseminou-se na população de equídeos no Brasil (DIEL et al., 2006; COSTA et al., 2008). Há poucos estudos de soroprevalência no País e os dados gerados indicaram a ocorrência de anticorpos anti-EHV bastante variável (4,5 a 84,7\%) (VARGAS \& WEIBLEN, 1991; MOREIRA et al., 1998; CARVALHO et al., 2000; DIEL et al., 2006; AGUIAR et al., 2008; COSTA et al., 2008).

O propósito deste trabalho foi investigar a presença de anticorpos anti-Neospora spp. e anti-EHV em equideos de tração, utilizados pelos recicladores de lixo residentes no bairro Alto de Santa Maria, RS, e vinculados ao projeto de extensão da Universidade Federal de Santa Maria "Programa de Ação Social Amigos do Carroceiro (PASAC)". Foram utilizadas 91 amostras de soro de equinos, SRD, de ambos os sexos, com idade de 3 a 20 anos. Os animais não apresentavam sinais clínicos evidentes de infecções associadas ao Neospora spp. e ao EHV. Os equinos eram alocados sob pastejo em terrenos baldios peridomiciliares da cidade e mantinham contato com o lixo depositado nessas áreas e com animais errantes como: cães, gatos, pequenos roedores e aves domésticas e silvestres. Para a obtenção dos soros, as amostras de sangue foram coletadas por punção da veia jugular no período de março de 2006 a maio de 2008. Para detecção de anticorpos anti-Neospora spp., foi utilizada a técnica de imunofluorescência indireta (IFI) (DUBEYet al., 1999a), empregando-se como controles positivo e negativo soro de equinos previamente testados para Neospora spp. (Universidade Estadual de Londrina).
O ponto de corte da reação foi o título 50 e a cepa de $N$. caninum NC-1 (Universidade de São Paulo) foi utilizada como antígeno. A pesquisa de anticorpos anti-EHV foi testada pela soroneutralização (SN), baseada na técnica de DIEL et al. (2006), usando-se a cepa Campus do EHV-1 e as células RK-13.

Das amostras de soros analisadas 15,4\%(14/ 91) foram reagentes para o Neospora spp. e todas foram negativas para o EHV. A presença de anticorpos antiNeospora spp., observada neste estudo, foi similar aos resultados obtidos por VILLALOBOS et al., (2006), que relataram a ocorrência de $15,1 \%$ de positividade ao $N$. caninum pela IFI, em éguas que apresentaram desordens reprodutivas associadas com detecção de anticorpos anti-EHV-1 e 5,8\% de soropositividade em equinos aparentemente saudáveis. No entanto, neste estudo, não foi encontrada associação da presença de anticorpos anti-Neospora spp e EHV-1. Vários estudos epidemiológicos usando técnicas de diagnóstico sorológico diferenciadas, em populações de equinos clinicamente saudáveis, foram conduzidos em diferentes países onde os índices de prevalência oscilaram de 2 a 30,2\% (DUBEY et al., 1999b; PITEL et al., 2001; VARDELEON et al., 2001; GUPTA et al., 2002; CIARAMELLA et al., 2004). No Brasil e na Argentina, não foi possível detectar anticorpos anti-Neospora spp. em equinos clinicamente sadios, quando utilizados testes de aglutinaçãao (DUBEY et al., 1999a). Porém, com o teste de ELISA, HOANE et al. (2006) observaram uma prevalência de $2,5 \%$ de anticorpos. No estudo realizado por LOCATELLI-DITTRICH et al. (2006), foram encontrados anticorpos reagentes ao $N$. caninum pela IFI em $47 \%$ dos soros das éguas testadas na diluição de 1:50 e em 13,8\% dos mesmos soros na diluição de 1:100. Nas triagens sorológicas para a neosporose pela IFI, utilizando-se o ponto de corte 50, observa-se o aumento da sensibilidade do teste e, como benefício, verifica-se a maior capacidade de detecção de animais infectados ou potencialmente infectados; porém existe a possibilidade de ocorrerem resultados falsos positivos (exposição ao parasita ou reação cruzada com parasitas que compartilham sítios antigênicos) ou não expressar uma infecção ativa (VARDELEON et al., 2001; LOCATELLI-DITTRICHet al., 2006). Na neosporose equina, deve-se considerar a infecção tanto pelo $N$. caninum quanto pelo $N$. hughesi, pois a maioria dos isolados de Neospora spp. em equinos foi identificada como $N$. hughesi; porém, atualmente, a relativa importância de ambos agentes ainda é desconhecida (JAKUBEK et al., 2006). Os resultados encontrados demonstraram que o Neospora spp. está presente na população de equinos estudada. Nesse sentido, provavelmente as fontes de infecção 
desses animais foram cães eliminadores de oocistos. Entretanto, não pode ser excluída a hipótese de que uma parcela desses animais possa ter sido infectada pela via transplacentária.

A ausência de anticorpos anti-EHV demonstrada neste estudo difere dos resultados obtidos por DIEL et al. (2006), os quais verificaram uma frequência de anticorpos em $4,5 \%$ das amostras testadas em equinos utilizados para esporte, provenientes de 65 municípios do RS, sendo uma população diferenciada do presente estudo. As amostras aqui avaliadas não foram estratificadas em diferentes categorias como idade, sexo e raça, devido à incongruência nos registros dos prontuários clínicos obtidos no PASAC, o que não permitiu uma análise mais detalhada da epidemiologia neste grupo. Considerando-se o status sanitário da categoria animal estudada, a qual não recebe cuidados adequados devido à carência econômica dos proprietários, verificou-se que os cavalos não receberam nenhum tipo de vacina, o que pode auxiliar na justificação para a ausência de anticorpos obtida neste trabalho. Por outro lado, sabe-se que a SN não é o teste mais sensível para detecção de anticorpos. CARVALHO et al. (2000) demonstraram que o teste de ELISA foi mais sensível e eficiente em detectar anticorpos específicos anti-EHV1 no soro sanguíneo e na porção plasmática do leite, quando comparado ao SN. Este estudo foi a primeira investigação da infecção pelo Neospora spp. e EHV em uma população de cavalos de tração na região central do RS. Observou-se que o Neospora spp. circula entre os equinos da população estudada, no entanto, a infecção pelo EHV não foi comprovada. Futuras investigações devem ser realizadas no intuito de avaliar o impacto da neosporose equina na saúde animal e seu potencial zoonótico.

\section{REFERÊNCIAS}

AGUIAR D.M.et al. Prevalência de anticorpos contra agentes virais e bacterianos em eqüídeos do Município de Monte Negro, Rondônia, Amazônia Ocidental Brasileira. Brazilian Journal of Veterinary Research.Animal Science, v.45, n.4, p.269276, 2008 .

CARVALHO R. et al. Use of an ELISA system for detection of equine herpesvirus 1 (EHV-1) antibodies in non-symptomatic pregnant mares and neonatal foals. Arquivos Brasileiros de Medicina Veterinária e Zootecnia, v.52, p.200-207, 2000.

CIARAMELLA P. et al. Seroprevalence of Neospora spp. in asymptomatic horses in Italy. Veterinary Parasitology, n.123, p.11-15, 2004.

COSTA E.A. et al. Meningoencephalitis in a horse associated with equine herpesvirus 1. Arquivo Brasileiro de Medicina Veterinária e Zootecnia, v.60, p.580-1583, 2008.
DIEL D.G. et al. Prevalência de anticorpos contra o vírus da influenza, da arterite viral e herpesvírus em equinos do Estado do Rio Grande do Sul, Brasil. Ciência Rural, v.36, p.14671473, 2006.

DUBEY J.P. et al. Serologic prevalence of Sarcocystis neurona, Toxoplasma gondii, and Neospora caninum in horses from Brazil. Journal of American Veterinary Medicine Association, v.215, p.970-972, 1999a.

DUBEY J.P. et al. Prevalence of antibodies to Neospora caninum in horses in North America. Journal of. Parasitology, v.85, p. 968-969, 1999 b.

DUBEY, J.P. Review of Neospora caninum and neosporosis in animals. Korean Journal of Parasitology, v.41, p.1-16, 2003.

FAO. Agricultural data-FAOSTAT. 2007. Capturado em 26 de janeiro de 2010. Online. Disponível na Internet: <http:// faostat.fao.org/faostat/collections? subset=agriculture $>$.

FLORES, E.F. Virologia veterinária. Santa Maria: UFSM, 2007. 888p.

GUPTA G.D. et al. Seroprevalence of Neospora spp., Toxoplasma gondii, and Sarcocystis neurona antibodies in horses from Jeju island, South Korea. Veterinary Parasitology, v.106, p.193-201, 2002

HOANE J.S. et al. Prevalence of Sarcocystis neurona and Neospora spp. infection in horses from Brazil based on presence of serum antibodies to parasite surface antigen. Veterinary Parasitology, v.136, p.155-159, 2006.

JAKUBEK E.B. et al. Seroprevalences of Toxoplasma gondii and Neospora sp. infections in Swedish horses. Veterinary Parasitology, v.138, p.194-199, 2006.

LOCATELLI-DITTRICH R. et al. Investigation of Neospora sp. and Toxoplasma gondii antibodies in mares and in precolostral foals from Parana state, Southern Brazil. Veterinary Parasitology, v.135, p.215-221, 2006.

MOREIRA N. et al. Aspectos etiológicos e epidemiológicos do aborto eqüino. Archives of Veterinary Sciences, v.3, p.25$30,1998$.

NILSON M.R.; CORRÊA W.N. Isolamento do vírus do aborto equino no estado de São Paulo. Arquivos do Instituto Biológico, v.31, p.23-35, 1966.

PITEL P.H. et al. Prevalence of antibodies to Neospora caninum in horses in France. Equine Veterinary Journal, v.33, p.205-207, 2001.

VARGAS A.C.P.; WEIBLEN R. Prevalência de anticorpos contra o herpesvírus equino tipo 1 em equinos de alguns municípios no Estado de Rio Grande do Sul. A Hora Veterinária, v.59, p.5-8, 1991.

VARDELEON D. et al. Prevalence of Neospora hughesi and Sarcocystis neurona antibodies in horses from various geographical locations. Veterinary Parasitology, v.95, p.273282, 2001.

VILLALOBOS E.M.C. et al. Association between the presence of serum antibodies against Neospora spp. and fetal loss in equines. Veterinary Parasitology, v.142, p.372-375, 2006. 